\title{
SYNTHESIS, CHARACTERIZATION AND ANTI-INFLAMMATORY ACTIVITY OF SOME HYDRAZONE DERIVATIVES
}

\author{
${ }^{1}$ Dr. Kamal Singh rathore, ${ }^{2}$ Gunjan Jadon* \\ ${ }^{1}$ B N Institute of Pharmaceutical Science, Udaipur, Rajasthan, India \\ ${ }^{2}$ Shrinathji Institute of Pharmacy, Nathdwara, Rajasthan, India \\ *Corresponding Author's E mail: jadon_gunjan@yahoo.in
}

\begin{abstract}
S:
A mixture of phenyl acetic acid (10gm, 0.003mole) in acetone, dimethyl Sulphate $(10.45 \mathrm{ml}, 0.007 \mathrm{~mole})$, anhydrous potassium carbonate $(2.8 \mathrm{gm}, 0.02 \mathrm{~mol})$ was refluxed on a water bath for $2 \mathrm{hr}$ with occasional stirring give methyl 2-phenylacetate(1), Methyl 2-phenylacetate $(1.78 \mathrm{gm}, 0.01 \mathrm{~mole})$ in alcohol was refluxed with hydrazine hydrate $(0.38 \mathrm{gm}, 0.01 \mathrm{~mole})$ for $8 \mathrm{hrs}$ formed 2-phenylacetohydrazide, A mixture of substituted benzaldehyde (1.22gm, $0.01 \mathrm{~mole})$ and 2-phenyl acetohydrazide $(1.5 \mathrm{gm}, 0.01$ mole) were dissolved in methanol then two drops of conc. $\mathrm{HCl}$ were added as catalyst and stirred at room temperature for $2 \mathrm{hr}$ formed $\mathrm{N}^{\prime}$-(2-chlorobenzylidene)-2-phenylacetohydrazide, $\mathrm{N}^{\prime}$-(3,4,5-trimethoxybenzylidene)-2phenylacetohydrazide, N'-(furan-2-ylmethylene) -2-phenylacetohydrazide, and $\mathrm{N}^{\prime}$-(3,4,5-trimethoxybenzylidene) -2phenylacetohydrazide
\end{abstract}

Key-Words: Phenyl acetic acid, Hydrazine-hydrate, NSAID’S, Anti-inflammatory.

\section{INTRODUCTION:}

Nonsteroidal anti-inflammatory drugs (NSAIDs) are the most commonly used drugs in inflammatory diseases, since they are effective in management of pain, fever, redness, edema arising as a consequence of inflammatory mediator release.

\section{COX Iso-enzymes}

Until the beginning of the 1990s, it had been thought that there was only one COX enzyme. In 1990, rapid development of the studies in this field revealed that COX enzyme had two distinct isoforms with different genetic coding. Although both isoforms had similar amino acid sequence and catalytic activity, they were demonstrated to have different functions. These isoforms were named 'constitutive' COX-1 and 'inducible' COX2. COX-1 catalyzes the formation of cytoprotective prostaglandins (PGs) in thrombocytes, vascular endothelium, stomach mucosa, kidneys, pancreas, Langerhans islets, seminal vesicles, and brain. In the first step in the biosynthesis of prostanoids catalyzed by phospholipase $\mathrm{A}_{2}$ is arachidonic acid (AA) release from the membrane phospholipids. The second step is AA conversion by cyclooxygenase. First, the unstable $\mathrm{PGG}_{2}$ is produced in the $\mathrm{COX}$ reaction, which is then immediately converted into $\mathrm{PGH}_{2}$ by the same enzyme in a peroxidase reaction. The end products of the AA metabolism are PGs, thromboxanes and prostacyclin. Induction of COX-2 by various growth factors, proinflammatory agents, endotoxins, mitogens, tumor agents indicates that this isoform may have a role in formation of pathological processes, such as inflammation. COX-1 products, prostaglandins $\left(\mathrm{PGI}_{2}\right.$ and $\mathrm{PGE}_{2}$ ), maintain integrity of gastrointestinal system (GIS) by reducing gastric acid secretion, increasing the thickness of mucus layer, stimulating bicarbonate secretion and enhancing mucosal blood flow. $\mathrm{PGE}_{2}$ enhances mucus secretion by activating cAMP in gastric epithelial cells. Glucocorticoids and endogenous steroids can suppress the gene responsible for COX-2 synthesis. Drugs, which inhibit COX-1 more than COX-2, such as indomethacin, naproxen, ibuprofen, cause more severe damage to the gastric tissues. As a result of studies focused on reduction of the adverse effects of NSAIDs, selective COX-2 inhibitors, such as celecoxib and rofecoxib, have been developed.

\section{Schiff Base}

A Schiff base, named after Hugo Schiff, is a compound with a functional group that contains a carbonnitrogen double bond with the nitrogen atom connected to an aryl or alkyl group, not hydrogen. ${ }^{[1]}$ Schiff bases in a broad sense have the general formula $R^{1} R^{2} C=N R^{3}$, where $\mathrm{R}$ is an organic side chain. In this definition,Schiff base is synonymous with azomethine. Some restrict the term to the secondary aldimines (azomethines where the carbon is connected to a hydrogen atom), thus with the general formula $\mathrm{RCH}=\mathrm{NR}^{\prime}$. ${ }^{[2]}$

\section{Hydrazones}

Hydrazones are a class of organic compounds with the structure $\mathrm{R}_{1} \mathrm{R}_{2} \mathrm{C}=\mathrm{NNH}_{2}$. ${ }^{[6]}$ They are related to ketones and aldehydes by the replacement of the oxygen with the $\mathrm{NNH}_{2}$ functional group. They are formed usually by the action of hydrazine on ketones or aldehydes. ${ }^{[7][8]}$

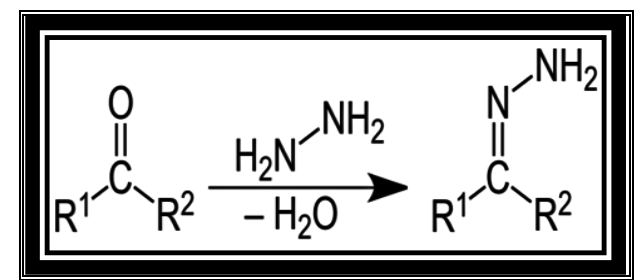


Sham. M. Sondhi. (2009) have report anti-inflammatory activity of some sulphono hydrozones.

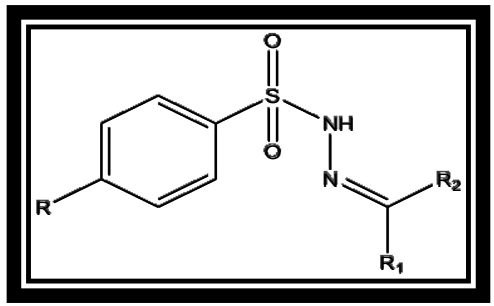

Sham. M. Sondhi. et.al. (2006) have report antiinflammatory and analgesic activity of some sulphono hydrozones.

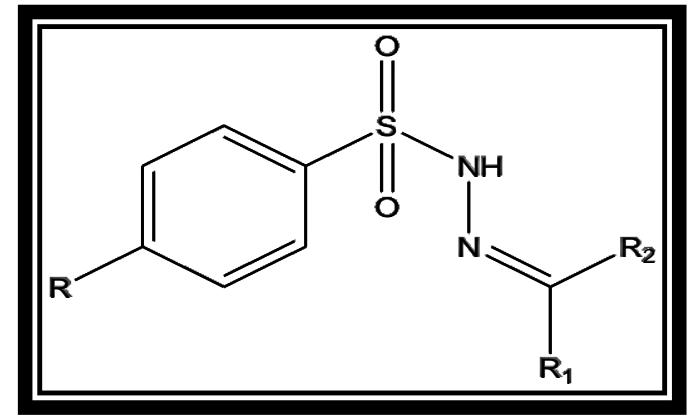

Vora. J.J. et.al. (2009) have reported synthesis and microbial studies of some novel schiff bases derivatives of 4-methyl pyridin-2-amine.

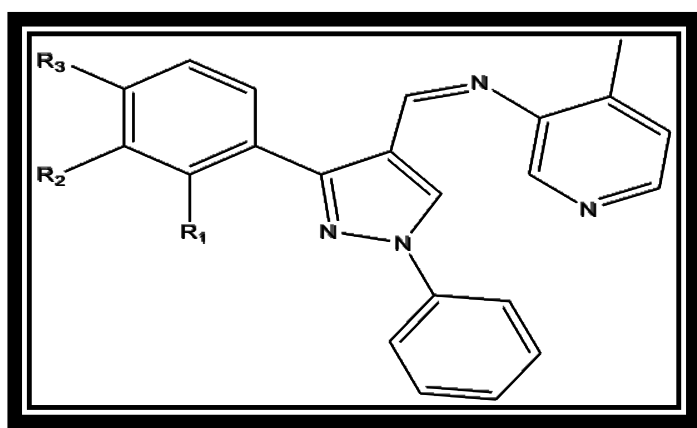

Salgin G. U. et.al. (2007) have reported the synthesis of some 2 -[2-(5-methyl-2-benzoxazolinone-3-yl)-acetyl]-4substituted hydrazone derivatives with potent analgesicinflammatory and antimicrobial activity.

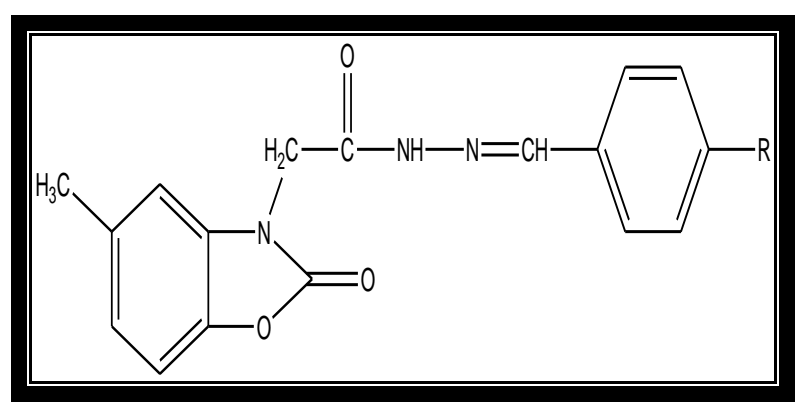

Our aim is to synthesize some newer schiff's bases of phenyl acetic acid with potent anti-inflammatory activity with lesser side effects.

The resarch work will be comprised of following steps.

1. Synthesis phenyl acetic acid hydrazone derivatives.

2. Physicochemical characterization of synthesized the structural features of these derivatives.

\section{MATERIAL AND METHODS}

Target Molecule:

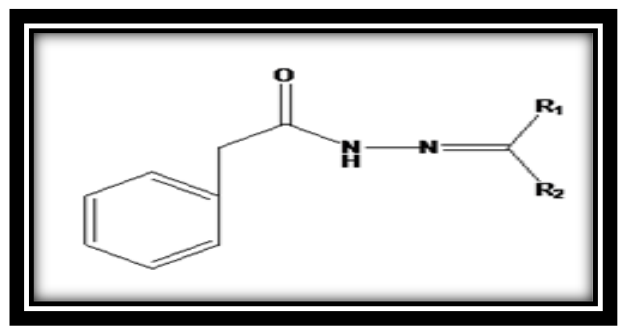

Synthetic scheme:

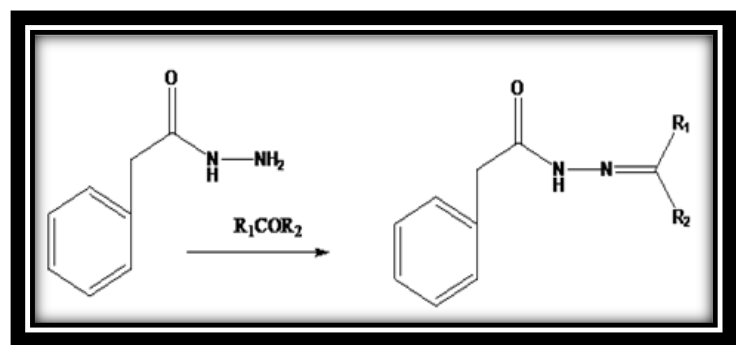

Synthetic procedure:

\section{Synthesis of $-2 a$}

A mixture of 2-chloro benzaldehyde (1.39gm, 0.01mole) and 2-phenyl acetohydrazide (1.5gm, 0.01mole) were dissolved in methanol then two drops of conc. $\mathrm{HCl}$ were added as catalyst and stirred at room temperature for $3 \mathrm{hr}$. the reaction mixture was poured into ice and filtered. The crude product so obtained was dried and recrystallized with methanol.

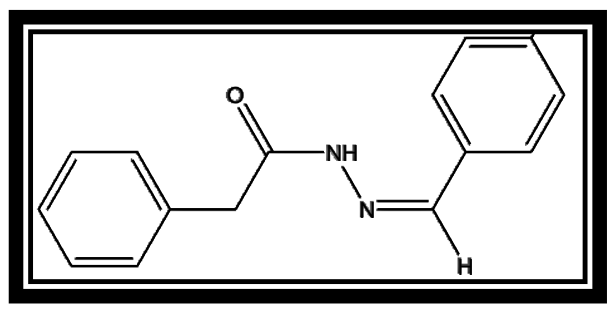

N'-(2-chlorobenzylidene)-2-phenylacetohydrazide

\section{Synthesis of $-2 b$}

A mixture of benzaldehyde (1.06gm, 0.01mole) and 2phenyl acetohydrazide ( $1.5 \mathrm{gm}, 0.01 \mathrm{~mole})$ were dissolved in methanol then two drops of conc. $\mathrm{HCl}$ were added as catalyst and stirred at room temperature for $4 \mathrm{hr}$. the reaction mixture was poured into ice and filtered. The crude product so obtained was dried and recrystallized with methanol.

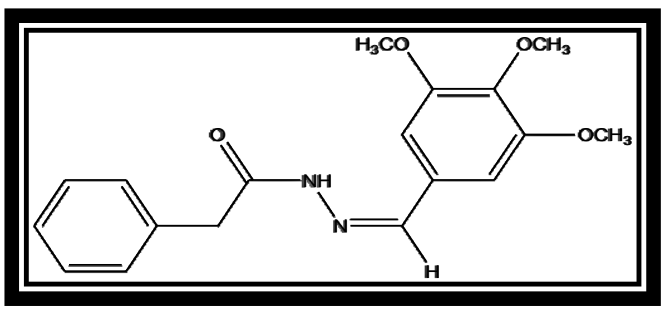

$\mathrm{N}^{\prime}$-(3,4,5-trimethoxybenzylidene)-2phenylacetohydrazide 


\section{Synthesis of $-2 c$}

A mixture of furfuraldehyde (.96gm, 0.01mole) 2-phenyl acetohydrazide $(1.5 \mathrm{gm}, 0.01 \mathrm{~mole})$ were dissolved in methanol then two drops of conc. $\mathrm{HCl}$ were added as catalyst and stirred at room temperature for 4 an half hr. the reaction mixture was poured into ice and filtered. The crude product so obtained was dried and recrystallized with methanol.

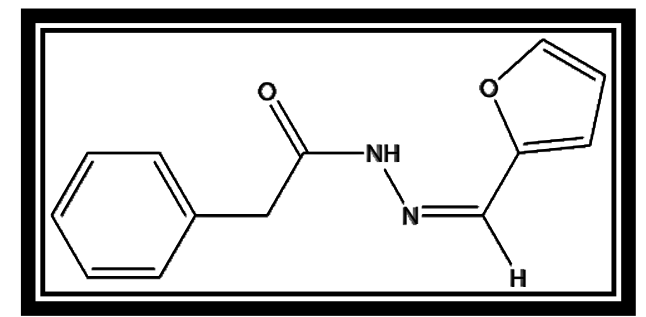

$N^{\prime}$-(furan-2-ylmethylene)-2-phenylacetohydrazide

\section{Synthesis of $-2 d$}

A mixture of p-hydroxy acetophenone (1.36gm, 0.01 mole) 2-phenyl acetohydrazide $(1.5 \mathrm{gm}, 0.01 \mathrm{~mole})$ were dissolved in methanol then two drops of conc. $\mathrm{HCl}$ were added as catalyst and stirred at room temperature for $4 \mathrm{hr}$. the reaction mixture was poured into ice and filtered. The crude product so obtained was dried and recrystallized with methanol.

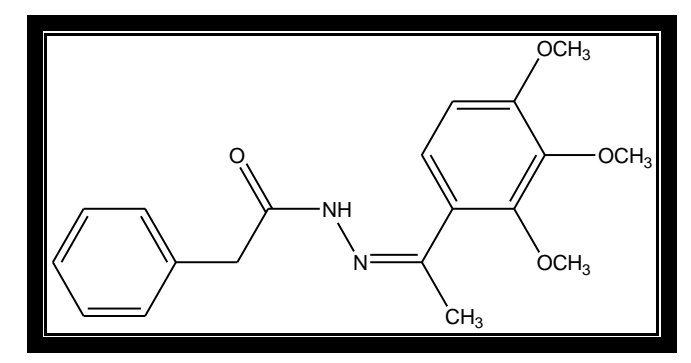

$$
\begin{aligned}
& \text { N'-(1-(4-hydroxyhenyl)ethylidene)-2- } \\
& \text { phenylacetohydrazide }
\end{aligned}
$$

Biological Evaluation:

\section{Anti-inflammatory activity:}

Animals Albino wistar rats, weighing 200-300 g, were used for experiments. The animals were kept in colony cages (6 rats each), maintained on a standard pellet diet with water, and left for 2 days for acclimatization before the experimental session. The food was withdrawn on the day before the experiment, but free access to water was allowed. All experiments were carried out according to the suggested ethical guidelines for the care of laboratory animals.

Selection of experimental animals: Healthy Albino wistar male rats weighing between 200-300 gm were used for the evaluation of anti- inflammatory activity. The animals were obtained from Zydus Research Centre, Ahmedabad.

Laboratory conditions: The rats were housed comfortably in a group of six in a single clean plastic cage with a metal frame lid on its top. Environmental room should be $22^{\circ} \mathrm{C}\left( \pm 3^{\circ} \mathrm{C}\right)$ relative humidity was at least $30 \%$ and preferably not exceed $70 \%$ other than during room cleaning the aim was to maintain between
$50-60 \%$. Lighting was to be artificial, the sequence being 12 hours light and 12 hours.

Food and water: All animals had free access to water and standard palletized laboratory animal diet.

Bedding: In the present study animals were provided with clean paddy husk bedding. Bedding was changed every alternate day to maintain proper hygienic conditions.

Acute Toxicity Studies -The acute toxicity of naphthalene derivatives was determined by using Albino wistar rats (200-300 gm) before taking the antiinflammatory activity. The animals were fasted for 24 hours prior to the experiment and up and down procedure (OECD Guideline no.425) method of CPCSEA was adopted for acute toxicity studies. Newly synthesized compounds suspended in tween-80 was administered to the group of rats $(\mathrm{n}=3)$ up to dose level of $10 \mathrm{mg} / \mathrm{kg}$. Animals were placed in individual plastic cage and observed at least once daily for the first 30 minutes and periodically for 24 hours to observe for sign of toxicity.

The anti-inflammatory activity of newly synthesized Hydrazide derivatives were carried out using carrageenan induced rat hind paw edema method.

Method: - Inhibition of carrageenan induced inflammation in rat paw Animals used:-Albino wistar rat No. of animals used per group:-6 rats Dose of test compound:-3 mg/kg Dose of standard drug:-3 mg/kg (Indomethacin) Route of administration:-Intra peritoneal (suspended in 1\% tween-80 solution)

Requirements: - Instruments:-Mercury displacement plethysmometer. Inflammation inducing agent:carrageenan solution $(1 \% \mathrm{w} / \mathrm{v})$ in saline solution was prepared and injected $(0.1 \mathrm{ml})$ in sub planter region to induce paw edema. Chemicals:-Tween-80 Standard drug:-Indomethacin $(3 \mathrm{mg} / \mathrm{kg})$ aqueous suspension was prepared using solution of tween-80 as a suspending agent. Test compounds:-suspension of compounds were prepared and administered intra peritoneal similar to that of standard drug.

Apparatus: -Syringes (1 $\mathrm{ml}, 2 \mathrm{ml})$, sample tubes (to prepare suspension of test compounds).

Experimental Design and Procedure: - Weigh the animals and number them. Mark the animals with picric acid for individual animal identification. Divide rats into 6 groups of 4 rats each. Note the initial paw volume of each rat by dipping just beyond tibio-tarsal junction by mercury displacement method, so that every time the paw is dipped in the mercury column up to the fixed mark to ensure constant paw volume. The animals were deprived of food overnight (allowed free access to water) and synthetic compounds were administered once before 30 minutes the injection of carrageenan. Dose volume not exceeding $0.5 \mathrm{ml} / 100 \mathrm{gm}$ intra peritoneal was administered. 


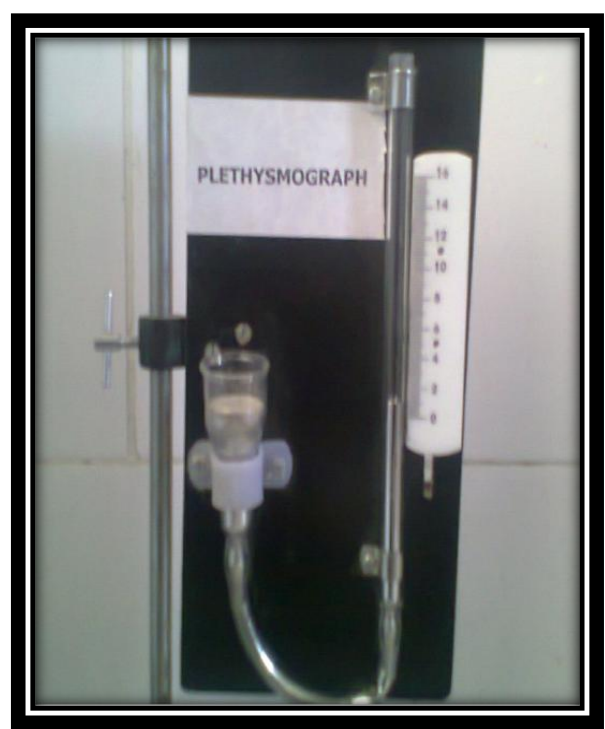

Figure 1: Plethysmometer

Group I:-The solvent control received normal saline. Group II:-Positive control received Diclofenac Sodium $(3 \mathrm{mg} / \mathrm{kg})$.

Group III:-Received Hydrazide derivative at a dose of 3 $\mathrm{mg} / \mathrm{kg}$ suspended in $1 \% \mathrm{w} / \mathrm{v}$ tween- 80 .

Group IV:-Received Hydrazide derivative- at a dose of 3 $\mathrm{mg} / \mathrm{kg}$ suspended in $1 \% \mathrm{w} / \mathrm{v}$ tween-80 Group

V:-Received Hydrazide derivative- at a dose of $3 \mathrm{mg} / \mathrm{kg}$ suspended in $1 \%$ w/v tween- 80 .

Group VI:-Received Hydrazide derivative- at a dose of $3 \mathrm{mg} / \mathrm{kg}$ suspended in $1 \% \mathrm{w} / \mathrm{v}$ tween- 80 .
After 30 minutes of test compound administration, 0.1 $\mathrm{ml}$ of $1 \% \mathrm{w} / \mathrm{v}$ of carrageenan in normal saline was injected in to the sub planter region of the left hind paw of rat. Immediately after the carrageenan injection, the volume of its displacement was measured using plethysmometer. The reading was recorded at $0,1 / 2,1,2$, 3 hrs.

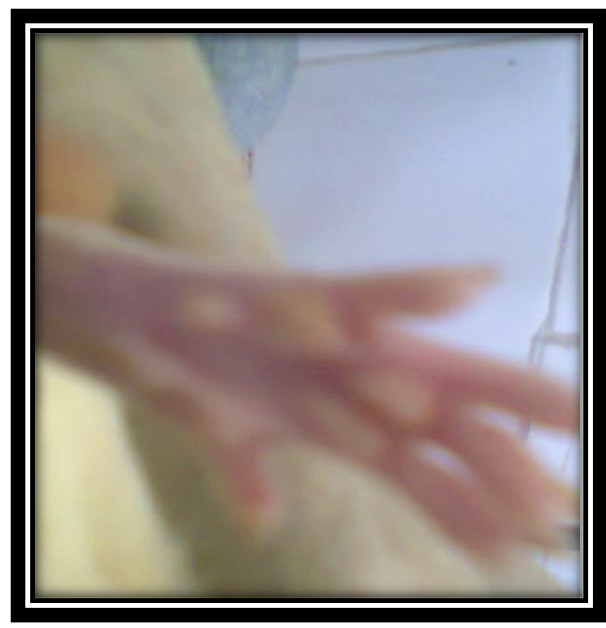

Figure 2: Carrageenan Induced Inflammation

The $\%$ inhibition of edema was calculated at the end of 3 hrs by using the formula ${ }^{[51]}$ Percent $(\%)$ inhibition $=1-$ Vt/Vc X 100, Where

Vt- edema volume in test group,

Vc-edema volume in control group

Results were expressed as mean \pm SEM (Standard Error of Mean).

\section{RESULT:}

\section{Screening of Anti-Inflammatory Activity}

Table 1:-Screening of Anti-inflammatory activity in Albino wistar rat

\begin{tabular}{|c|c|c|}
\hline COMPOUNDS & VOLUME OF EDEMA & \% INHIBITION \\
\hline Control(DMSO) & $.09375- \pm 0.00625$ & 0 \\
\hline Diclofenac sodium & $.03125 \pm 0.00625$ & 46.69 \\
\hline Comps 2a & $.0500 \pm 0.01768$ & 46.66 \\
\hline $2 \mathrm{~b}$ & $.0375 \pm 0.007217$ & 56.69 \\
\hline $2 \mathrm{c}$ & $.0500 \pm 0.01768$ & 52.01 \\
\hline $2 \mathrm{~d}$ & $.05625 \pm 0.01573$ & \\
\hline
\end{tabular}

The pharmacological screening of the synthesized compounds showed anti-inflammatory activity ranging from 33.33 to $66.66 \%$ inhibition of rat paw edema volume after 3 hours, whereas the standard drug Diclofenac sodium showed $66.66 \%$ inhibition of rat paw edema volume after 3 hours.
The compound $-2 \mathrm{c}$ and $2 \mathrm{~d}$ was found to be nearly more potent then Diclofenac sodium which is used as standard drug. A compound $-2 \mathrm{a}$ and $2 \mathrm{~b}$ has shown less activity then Diclofenac sodium. Compounds SE and SJ shown more potent activity than compound $-2 \mathrm{a}$ and $2 \mathrm{~d}$ and Diclofenac sodium. 
Physical characteristics:

\begin{tabular}{|c|c|l|c|c|}
\hline Compound code & Mol. Formula & \% yield & Melting point & Rf value \\
\hline $\mathbf{2 a}$ & $\mathbf{C}_{\mathbf{1 5}} \mathbf{H}_{\mathbf{1 3}} \mathbf{N}_{\mathbf{2}} \mathbf{O C l}$ & $\mathbf{7 5 \%}$ & 60.5 & 0.90 \\
\hline $\mathbf{2 b}$ & $\mathbf{C}_{\mathbf{1 3}} \mathbf{H}_{\mathbf{1 2}} \mathbf{N}_{\mathbf{2}} \mathbf{O}_{\mathbf{2}}$ & $\mathbf{6 5 . 2 9 \%}$ & 55.5 & 0.85 \\
\hline $\mathbf{2 c}$ & $\mathbf{C}_{\mathbf{1 8}} \mathbf{H}_{\mathbf{2 0}} \mathbf{N}_{\mathbf{2}} \mathbf{O}_{\mathbf{4}}$ & $\mathbf{4 4 . 0 5 \%}$ & 50.5 & 0.72 \\
\hline $\mathbf{2 d}$ & $\mathbf{C}_{\mathbf{1 7}} \mathbf{H}_{\mathbf{1 7}} \mathbf{N}_{\mathbf{2}} \mathbf{O}_{\mathbf{2}}$ & $\mathbf{4 6 . 5 5 \%}$ & 71 & 0.60 \\
\hline
\end{tabular}

Spectral analysis:

\begin{tabular}{|c|c|c|c|}
\hline Compound code & IR $\left(\mathrm{cm}^{1}\right)$ & Mass (m/e) & $\mathbf{1}^{\mathrm{H}}-\mathrm{NMR}$ \\
\hline $2 \mathbf{a}$ & $\begin{array}{l}\text { 3564.58(OH), 3105.18( } \mathrm{Ar}-\mathrm{CH}), \\
\text { 3104.44(NH), 1693.38(C=O), } \\
\left.\text { 1503.57(C=N), 1125.35( } \mathrm{OCH}_{3}\right)\end{array}$ & $\begin{array}{l}\mathrm{M}^{+} 279 \\
\text { Base peak } \\
261.1\end{array}$ & $\begin{array}{l}\text { 8.6(s,1H,NH }), 7.2-8.0(\mathrm{~m}, 9 \mathrm{H}, \mathrm{Ar}-\mathrm{H}) \\
6.7\left(\mathrm{~s}, 2 \mathrm{H}, \mathrm{CH}_{2}\right), 1.2(\mathrm{~s} 1 \mathrm{H}, \mathrm{CH})\end{array}$ \\
\hline $2 b$ & $\begin{array}{l}\text { 3469.70(OH), 3301.91(NH), } \\
\text { 3301.91(NH), 3195.91(NH), } \\
\text { 3031.89(Ar-CH), 1701.10(C=O), } \\
\text { 1546.8(CH) }\end{array}$ & $\begin{array}{l}\mathrm{M}^{+} 239 \\
\text { Base peak } 208\end{array}$ & $\begin{array}{l}\text { 9.8(s,1H,OH }), 8.5(\mathrm{~s}, 1 \mathrm{H}, \mathrm{NH}), 7.2- \\
\text { 7.8(m,9H,Ar-H }), 5.5\left(\mathrm{~s}, 2 \mathrm{H}, \mathrm{CH}_{2}\right) \\
1.6(\mathrm{~s}, 1 \mathrm{H}, \mathrm{CH})\end{array}$ \\
\hline $2 c$ & $\begin{array}{l}\text { 3124.95(NH), 2923.24( } \mathrm{Ar}-\mathrm{CH}) \\
1679.12(\mathrm{C}=\mathrm{O}), 1632.30(\mathrm{C}=\mathrm{N})\end{array}$ & $\begin{array}{l}\mathrm{M}^{+} 267 \\
\text { Base peak } 220\end{array}$ & $\begin{array}{l}\text { 8.9(s,1H,NH }), 7.7-8.3(\mathrm{~m}, 9 \mathrm{H}, \mathrm{Ar}-\mathrm{H}) \\
\text { 7.09(s,2H,CH}), 1.47(\mathrm{~s}, 1 \mathrm{H}, \mathrm{CH}) \\
3.1\left(\mathrm{~s}, 6 \mathrm{H}, \mathrm{N}\left(\mathrm{CH}_{3}\right)_{2}\right)\end{array}$ \\
\hline $2 d$ & $\begin{array}{l}\text { 3359.90(NH), 3199.24(NH), } \\
\text { 3097.28( } \mathrm{Ar}-\mathrm{CH}), 1696.54(\mathrm{C}=\mathrm{O}), \\
1516.19(\mathrm{C}=\mathrm{N}), 1299.60\left(\mathrm{~N}\left(\mathrm{CH}_{3}\right)_{2}\right)\end{array}$ & $\begin{array}{l}\mathrm{M}^{+} 272 \\
\text { Base peak } \\
235.5\end{array}$ & $\begin{array}{l}\text { 8.3(s1H,NH }), 7.2-8.2(\mathrm{~m}, 7 \mathrm{H}, \mathrm{Ar}-\mathrm{H}) \\
7.0\left(\mathrm{~s}, 2 \mathrm{H}, \mathrm{CH}_{2}\right), 4.0\left(\mathrm{~s}, 9 \mathrm{H}, \mathrm{OCH}_{3}\right)\end{array}$ \\
\hline
\end{tabular}

\section{CONCLUSION:}

From the above data I found the comp-2C and $2 \mathrm{~d}$ have near the potent drugs as I used Diclofenac Sodium.

\section{REFERENCE:}

1) Sham M, Dinodia M, Jain S, and Kumar A, Ind J Chem. 2009, 48B, 1128- $1136 .$.

2) Olcay B, and Hakan B, Article. 2009, 13, 2126-2135..

3) Vora JJ, Vasava SB, Parmar KC, Chauhan SK and Sharma SS, E J Chem. 2009, 6 (4), 1205-1210.

4) Salgn GU, Gokhan KN, Gokats O, Koysal Y, kthc E, Isik S, Aktay G,and Ozalp Med Chem. 2007, 15, 5738-5751.

5) Durate CD, Tributino JLM, Lacerda DI, and Martins Mv, Med Chem.2007, 15, 2421-2433. 

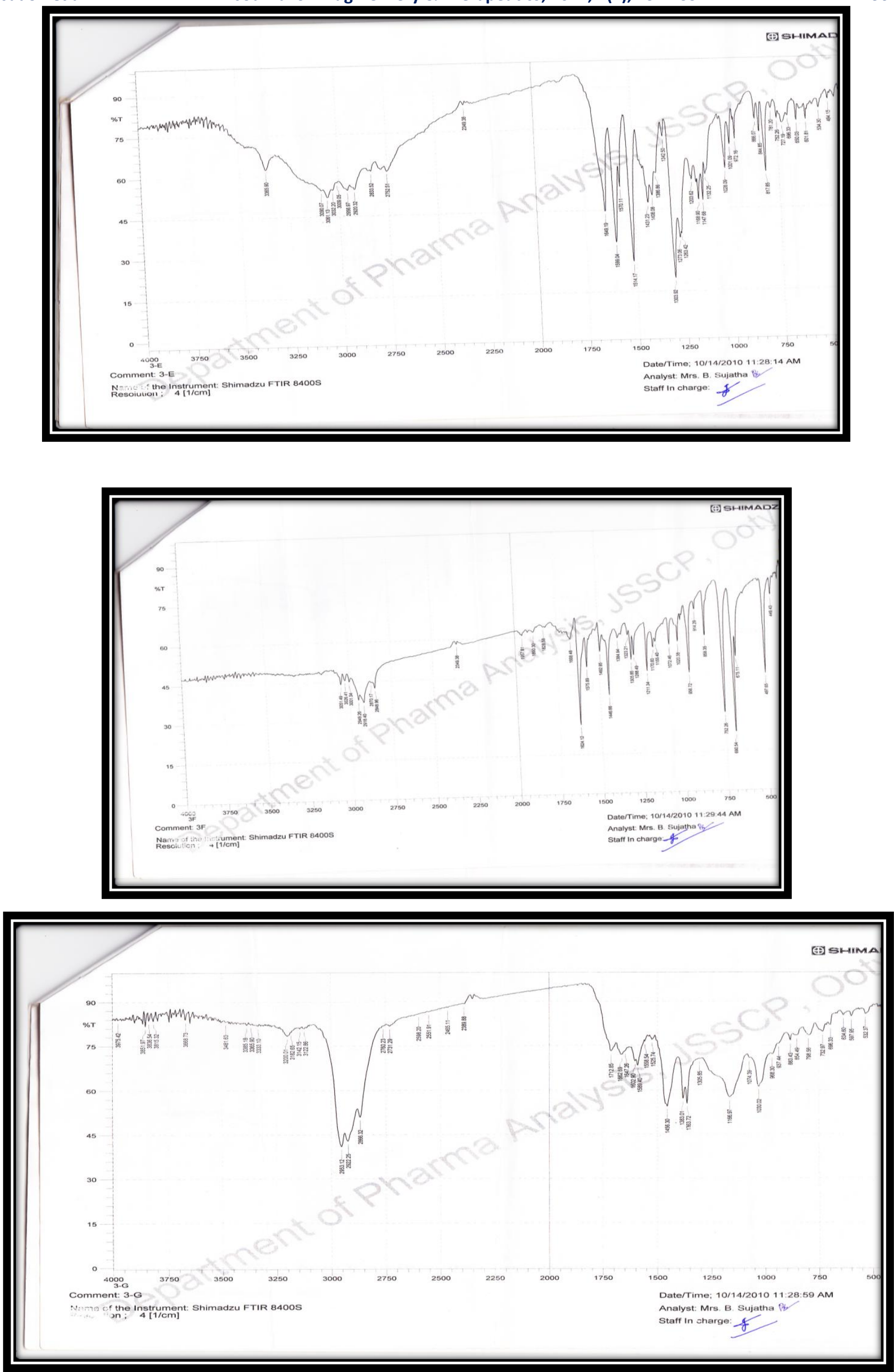

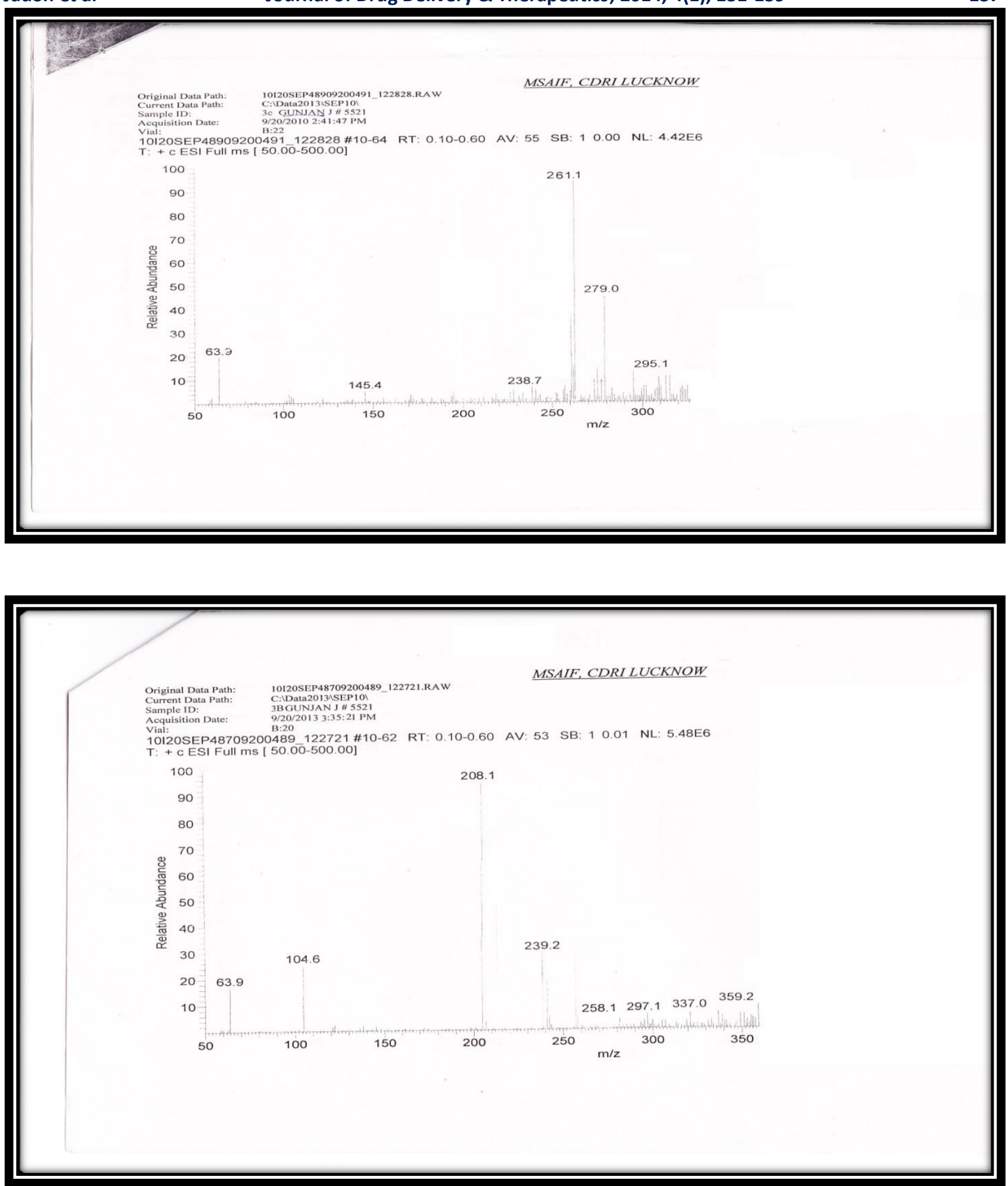

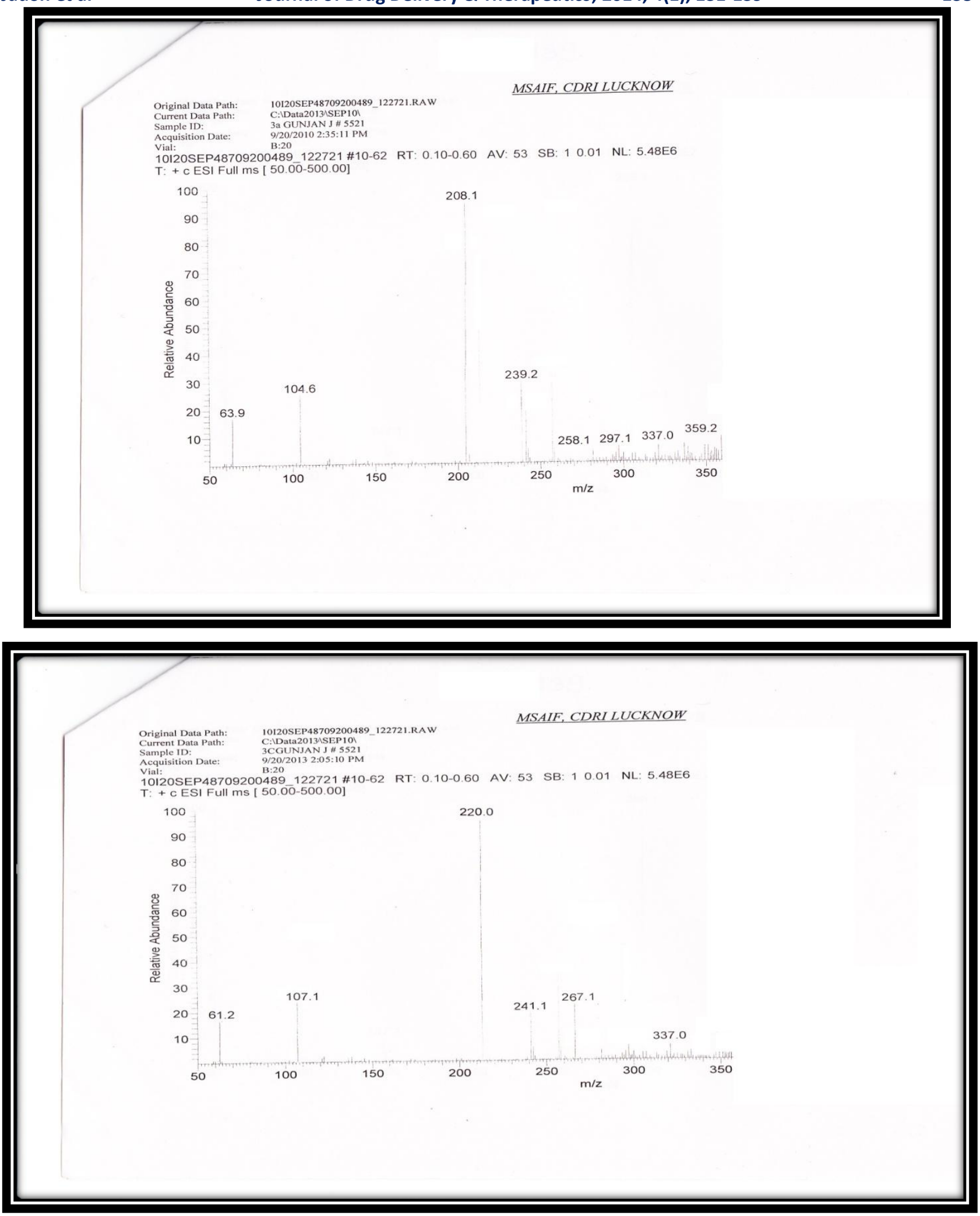

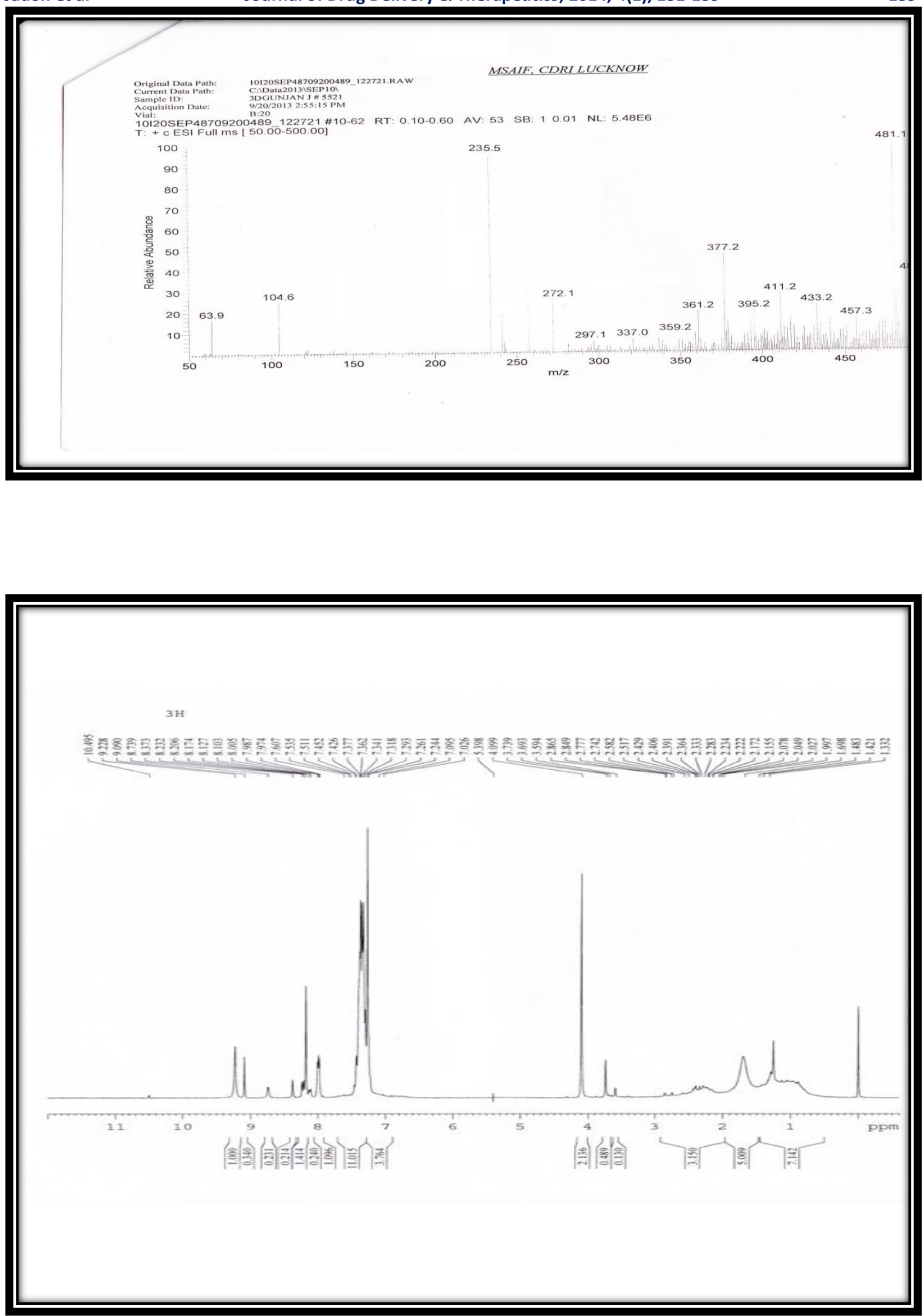